\title{
Observation of Mn-Ni-Si-rich Features in Thermally-Aged Model Reactor Pressure Vessel Steels
}

\author{
B. M. Jenkins ${ }^{a \star}$, P. D. Styman ${ }^{b \star}$, N. Riddlec, P. A. J. Bagot ${ }^{a}$, M. P. Moody ${ }^{a}$, G. D. W. Smith ${ }^{a}$, \\ J. M. Hyde Hab $^{\mathrm{a}}$ \\ a - Dept. of Materials, Parks Road, Oxford, OX13PH, UK \\ b - National Nuclear Laboratory, Building D5, First Floor, Culham Science Centre, Abingdon, \\ Oxfordshire, OX14 3DB \\ c - Rolls Royce, PO Box 2000, Raynesway, Derby DE21 7XX, UK \\ *Corresponding authors: benjamin.jenkins@materials.ox.ac.uk (B. M. Jenkins)
}

Keywords: Atom probe tomography phase transformations; bainitic steels; Mn-Ni-Si-rich features

\section{Abstract}

Atom probe tomography was used to characterise two low-Cu $(<0.04$ at. \%) model steels after exposure to long-term thermal ageing. Mn-Ni-Si-rich features were observed to form after as little as 20,731 hours ( 2.4 years) of ageing. The composition of these features were compared to those predicted by thermodynamic models and the similarities and differences are discussed.

\section{Main Text}

Extending the safe operational lifetime of nuclear power plants (NPPs) has very significant economic and environmental benefits. Safety cases to continue NPP operation beyond 60 years need to be founded on a thorough understanding of the developing embrittlement behaviour of the reactor pressure vessel (RPV) during operation.

After it was demonstrated that RPVs were susceptible to hardening-embrittlement due to the formation of Cu-rich precipitates during exposure to neutron irradiation and elevated temperatures, the Cu content of the ferritic steel and associated welds used to manufacture RPVs has since been more carefully controlled. However, numerous studies have shown that low-Cu RPV alloys still exhibit a detrimental increase in their hardness or ductile-tobrittle transition temperature after exposure to neutron irradiation[1-4]. One contribution to this hardening embrittlement is thought to be the formation of Mn-Ni-Si-rich features that have been characterised using TEM[5] and APT[6].

$\mathrm{Mn}-\mathrm{Ni}$-Si-rich features have been observed experimentally in neutron-irradiated samples[1,2,6-10] and are predicted to be stable by thermodynamic modelling, albeit by extrapolation from higher temperatures[11,12]. Determining if these features are thermodynamically stable is critical for the development of accurate lifetime models, particularly at extended times ( $>60$ years), and for models used to inform post-irradiation annealing procedures e.g.Reference[13]. However, Mn-Ni-Si-rich features have only been experimentally observed in materials exposed to high fluence and the chemical compositions of the observed features do not directly match with the theoretical stoichiometries predicted by models[14]. Hence, there is still discussion as to whether these features are thermodynamically stable phases[12,15], which form at an enhanced rate due to the damage induced during irradiation, or are irradiation-induced[16,17]. Recent annealing experiments indicate that the features which form during irradiation are stable at temperatures of 425 ${ }^{\circ} \mathrm{C}[18]$. 
Observation of Mn-Ni-Si-rich features formed under thermal ageing experiments conducted at temperatures similar to those experienced during operation would provide strong support for the thermodynamic stability of the features. Such experiments would also provide critical information on the accuracy of models which predict their formation and composition.

However, previous studies of low-Cu RPV steels that display an increase in hardness after long-term thermal ageing have not reported discrete Mn-Ni-Si-rich feature formation[19], although one $\mathrm{Mn}-\mathrm{Ni}$-Si-rich feature was observed at a grain boundary in high-Cu alloy[20].

In this work, two low-Cu model RPV alloys were subjected to long-term thermal ageing and characterised using atom probe tomography (APT). The compositions of these two alloys are provided in Table 1. The first alloy, WF, was a weld material that was thermally-aged at $330^{\circ} \mathrm{C}$ for 100,000 hours ( 11.4 years). Meanwhile, a plate alloy (I) was aged at $330^{\circ} \mathrm{C}$, $365^{\circ} \mathrm{C}$, and $405^{\circ} \mathrm{C}$, respectively, for 20,733 hours ( 2.4 years). Both alloys were vacuumsealed in quartz tubes prior to thermal ageing to limit oxidation. The compositions of these two alloys are provided in Table 1. WF samples were prepared for APT analysis via standard two-stage electropolishing[21], using $25 \%$ perchloric acid $(60 \%)$ in acetic acid with an applied voltage of $16 \mathrm{~V}$ for the first stage, whilst a solution of $2 \%$ perchloric $(60 \%)$ in 2 butoxy-ethanol was used at $8 \mathrm{~V}$ for the second stage. Specimens for alloy I were fabricated using a dual-beam scanning electron microscope (SEM)/focused-ion-beam (FIB); standard procedures[22,23], including a final polish at $2 \mathrm{kV}$ to limit Ga damage[24], were followed.

\begin{tabular}{|l|l|l|l|l|l|l|l|l|}
\hline Alloy & $\mathrm{Cu}$ & $\mathrm{Si}$ & $\mathrm{Ni}$ & $\mathrm{Mn}$ & $\mathrm{P}$ & $\mathrm{Cr}$ & $\mathrm{Mo}$ & $\mathrm{C}$ \\
\hline WF & 0.02 & 1.1 & 1.6 & 1.4 & 0.02 & 0.1 & 0.2 & 0.18 \\
\hline $\mathrm{I}$ & 0.04 & 1.1 & 3.1 & 1.4 & 0.01 & 0.1 & 0.27 & 0.87 \\
\hline
\end{tabular}

Table 1: Composition (at. \%) of the alloys used in this study.

Alloy WF was analysed using a LEAP 3000 X HR system, whilst Alloy I was studied using a LEAP 5000 XR system. Both alloys were analysed at $50 \mathrm{~K}$, with a pulse fraction of $20 \%$, a pulse frequency of $200 \mathrm{kHz}$, and a detection rate of $0.2 \%$. Reconstructions and data analyses were performed using IVAS 3.8.4, with the core-linkage[25] cluster search algorithm (a variant of the maximum separation method[26]) utilised to identify clustered atoms within each dataset. $\mathrm{Si}, \mathrm{Cu}, \mathrm{Ni}, \mathrm{Mn}, \mathrm{P}$ were chosen as core ions for the cluster searches, with the $29 \mathrm{Da}$ overlap between ${ }^{58} \mathrm{Fe}^{2+}$ and ${ }^{58} \mathrm{Ni}^{2+}$ included. $A D_{\max }$ value of $0.5 \mathrm{~nm}$ was used, with an $L=E=0.25 \mathrm{~nm}$. $\mathrm{N}_{\min }$ was selected to maximise the ratio of clusters detected in each dataset with respect to the number of clusters that were detected in a dataset in which the mass-to-charge-state ratio of each ion was randomly shuffled[27]; $\mathrm{N}_{\text {min }}$ varied between 20-40 atoms. Clusters that intersected the edge of the dataset were identified using the methods outlined in Ref. [28] - edge clusters were calculated as half for number density $\left(\mathrm{N}_{\mathrm{d}}\right)$ calculations. Due to the small number of detected clusters in each state, edge clusters were included in composition and size calculations. Whilst this is likely to result in a slight underestimate of actual precipitate sizes, the impact on calculated compositions will be minimal since the clusters did not display a core-shell or appendage type structures. The majority of the $\mathrm{Fe}$ in the clusters was presumed to be the result of artefacts in the APT data, so was not included in compositional calculations[5].

The APT atoms maps in Figure 1 (a) show the distribution of $\mathrm{Ni}, \mathrm{Mn}$, and $\mathrm{Si}$ atoms in an atom probe needle from alloy I after ageing at $330{ }^{\circ} \mathrm{C}$ for 20,733 hours. A grain boundary can be seen within the dataset, and a Mn-Ni-Si-rich feature was observed to have formed at the step on the grain boundary. In total, four datasets were collected for this alloy and over $70 \%$ of the detected clusters had nucleated on prominent heterogeneous nucleation sites, such as grain boundaries and dislocations. One dataset contained seven $\mathrm{Mn}-\mathrm{Ni}$-Si-rich clusters that appeared to have formed in the absence of a heterogeneous nucleation site, 
such as a dislocation (Figure $1(\mathrm{e})$ ). Whilst one cannot be certain that these features did not nucleate on a small dislocation loop or vacancy cluster, which would not necessarily be detected in the APT data due to limitations with the technique's detection efficiency and spatial resolution, they may have formed homogeneously within the matrix.

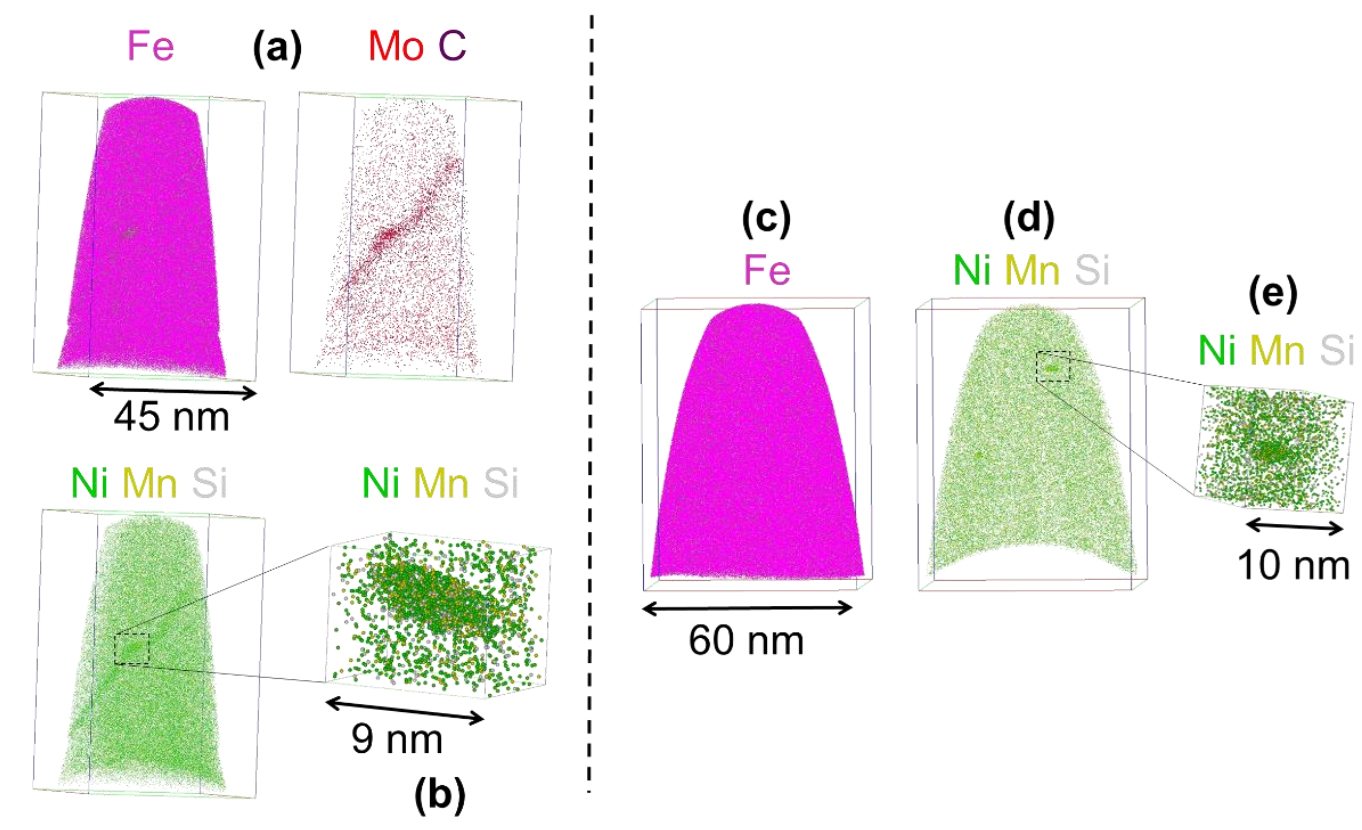

Figure 1: Atom maps for Alloy I that had been thermally aged for 20,700 hours are $330{ }^{\circ} \mathrm{C}$. (a) the distribution of $\mathrm{Fe}, \mathrm{Mo}, \mathrm{C}, \mathrm{Mn}, \mathrm{Ni}$, and Si atoms in one specimen. The bounding box has dimensions of $45 \mathrm{~nm} \times 45 \mathrm{~nm} \times 75 \mathrm{~nm}$. (b) Atom map showing an enlarged Mn-Ni-Si-rich precipitate (dimensions of bounding box = $7 \mathrm{~nm} \times 9 \mathrm{~nm} \times 7 \mathrm{~nm}$ ). (c) The distribution of Fe, Mn, Ni, Si atoms throughout another specimen, and (d) Distribution of Mn, Ni, and Si atoms in a $10 \mathrm{~nm}$ thick section of the dataset in (c). The bounding box has dimensions of $60 \mathrm{~nm} \times 60 \mathrm{~nm} \times 80$ $\mathrm{nm}$. (e) Atom map showing an enlarged Mn-Ni-Si-rich precipitate (dimensions of bounding box $=10 \mathrm{~nm} \times 10 \mathrm{~nm} \times$ $10 \mathrm{~nm})$.

Figure 2 (a) shows APT element maps for the $\mathrm{Fe}, \mathrm{Mn}, \mathrm{Ni}$, and $\mathrm{Si}$ atoms in a dataset from an alloy I sample that was aged for 20,700 hours at $365^{\circ} \mathrm{C}$. Two Mn-Ni-Si-rich clusters can be seen to have nucleated on a linear region that is enriched in Mo and $C$ (Figure 2 (b)), from which it can be inferred that nucleation has occurred on a dislocation. All of the clusters detected in this condition had nucleated on dislocations. 
(a)

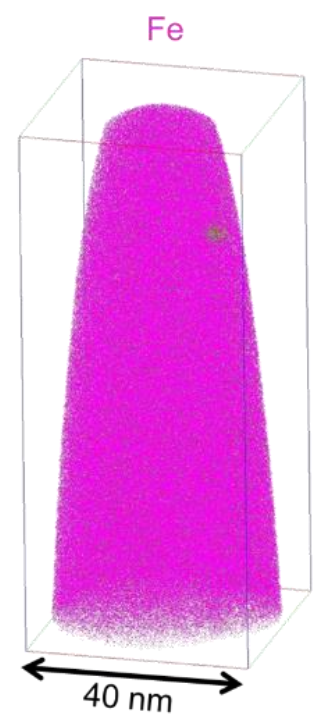

(b)

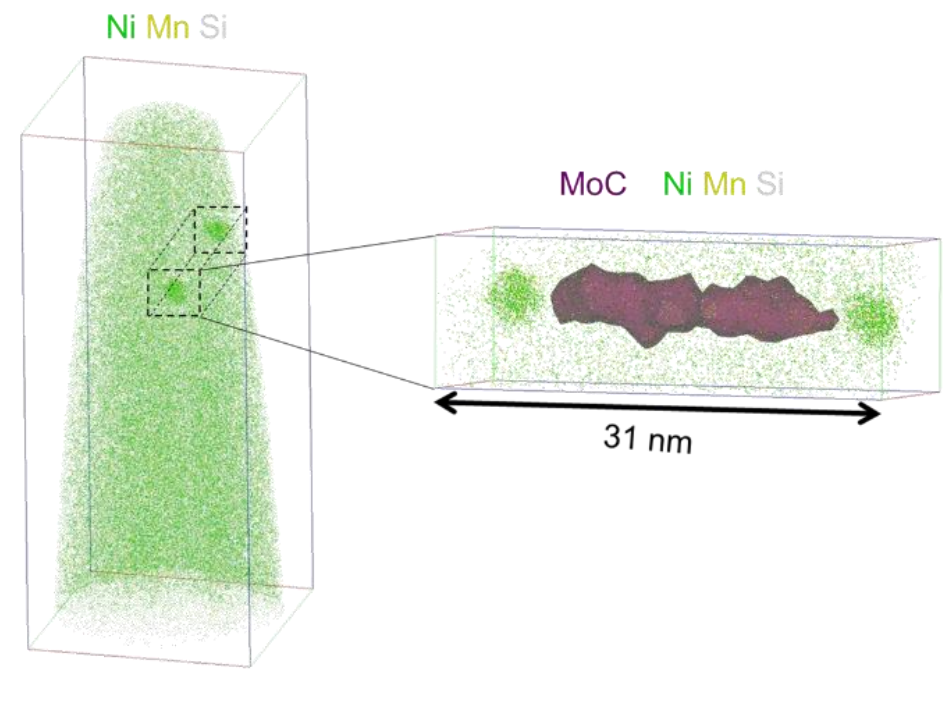

Figure 2: (a) Atom maps showing the distribution of Fe. Mn, Ni, and Si atoms in Alloy I that had been thermally aged for 20,700 hours are $365^{\circ} \mathrm{C}$. The bounding box has dimensions of $40 \mathrm{~nm} \times 40 \mathrm{~nm} \times 90 \mathrm{~nm}$. (b) An isosurface for 1 at. \% MoC is displayed to indicate the location of the dislocation. The bounding box has dimensions of $10 \mathrm{~nm} \times 10 \mathrm{~nm} \times 31 \mathrm{~nm}$.

Clustering was also observed in the alloy I samples that had been aged at $405^{\circ} \mathrm{C}$ for 20,700 hours. Similar to the $365^{\circ} \mathrm{C}$ samples, all of the clusters detected in this condition were observed to have heterogeneously nucleated on dislocations. Figure 3 shows one of the datasets that contained a $\mathrm{Mn}-\mathrm{Ni}$-Si-rich cluster, alongside a region that is enriched in Mo and C.
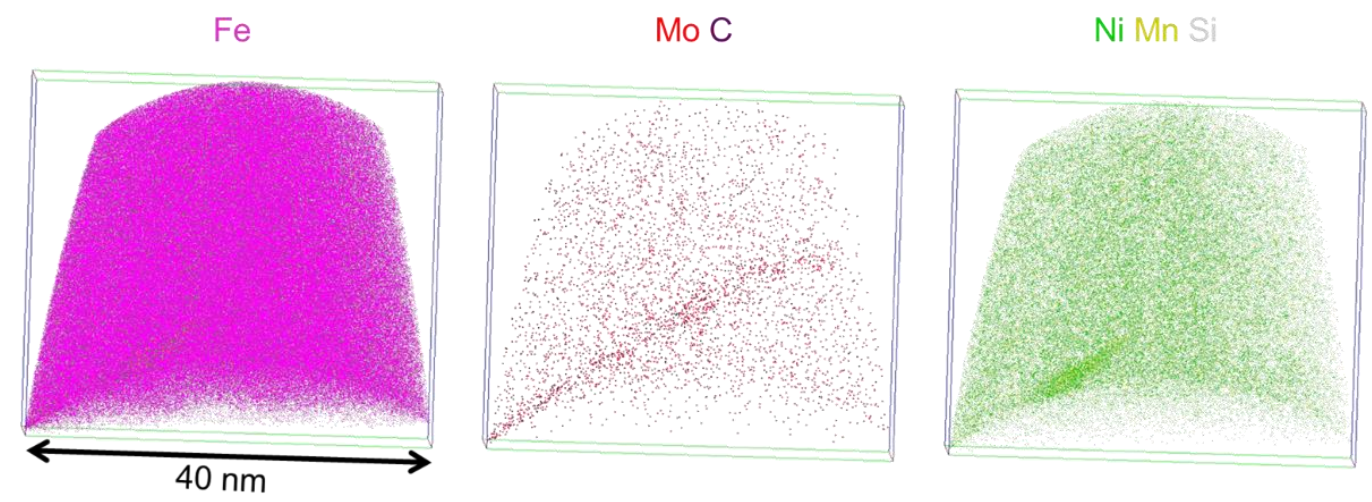

Figure 3: Atom maps showing the distribution of Fe, Mo, C, Mn, Ni, and Si atoms in Alloy I that had been thermally aged for 20,700 hours are $405^{\circ} \mathrm{C}$. The bounding box has dimensions of $45 \mathrm{~nm} \times 45 \mathrm{~nm} \times 40 \mathrm{~nm}$.

Figure 4 (a) shows atom maps for the WF sample that was aged at $330{ }^{\circ} \mathrm{C}$ for 100,000 hours. The segregation behaviour of $\mathrm{Mo}$ and $\mathrm{C}$ to a planar feature, with local areas more enriched in $\mathrm{Mo}$ and $\mathrm{C}$, indicates the presence of a low-angle grain boundary. Mn-Ni-Si-rich precipitates were observed to have formed on this feature (Figure 4 (b)). 
(a)

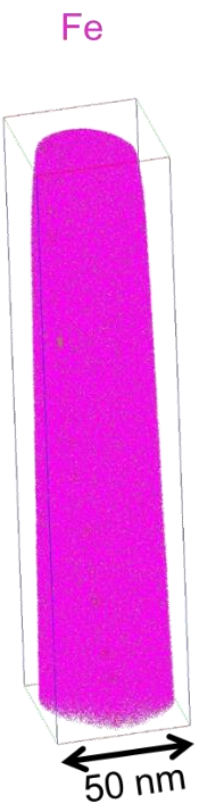

(a)

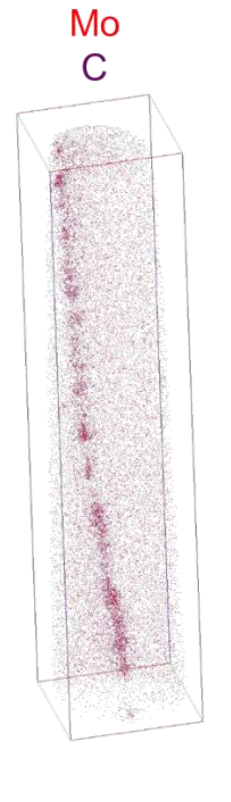

(b)

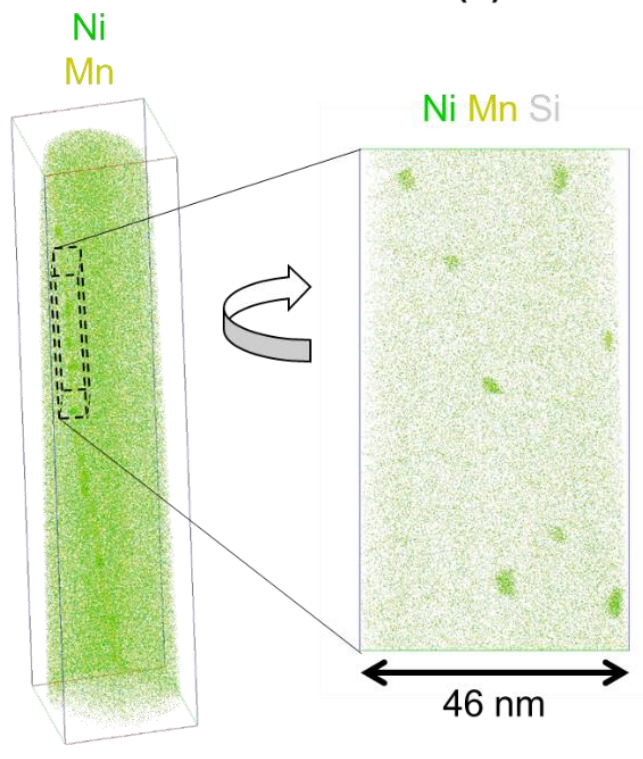

Figure 4: (a) Atom maps showing the distribution of Fe, Mo, C, Mn, and Ni, atoms in Alloy WF that had been thermally aged for 100,000 hours are $330^{\circ} \mathrm{C}$. The bounding box has dimensions of $50 \mathrm{~nm} \times 50 \mathrm{~nm} \times 230 \mathrm{~nm}$. (b) Atom map displaying the Mn, Ni, Si distribution in the region-of-interest outlined in (a) (The bounding box has dimensions of $15 \mathrm{~nm} \times 46 \mathrm{~nm} \times 86 \mathrm{~nm}$ ).

This observation of Mn-Ni-Si-rich features at $330^{\circ} \mathrm{C}, 365^{\circ} \mathrm{C}$, and $405^{\circ} \mathrm{C}$, is indicative of the thermodynamic stability of $\mathrm{Mn}, \mathrm{Ni}$, and $\mathrm{Si}$ solute clusters at this temperature. Since the majority of solute clustering was detected on heterogeneous nucleation sites in all four cases above, the reported cluster volume fractions and number densities are unlikely to accurately represent the values throughout the materials; therefore, counting errors are not presented for these parameters. However, they are provided for reference in Table 2.

Within alloy I, cluster size was observed to increase with ageing temperature. This is likely due to the increased diffusion distance of solute ions in a given time at elevated temperatures. Indeed, the clusters in the $405^{\circ} \mathrm{C}$ samples all intersected the edge of the analysed volume, so the reported size is a lower bound.

\begin{tabular}{|c|c|c|c|c|c|}
\hline Alloy & $\begin{array}{c}\text { Ageing } \\
\text { Temperature } \\
\left({ }^{\circ} \mathrm{C}\right)\end{array}$ & $\begin{array}{c}\text { Ageing } \\
\text { Time } \\
(\mathrm{h})\end{array}$ & $\begin{array}{c}\mathrm{N}_{\mathrm{d}} \\
\left(\times 10^{22} / \mathrm{m}^{3}\right)\end{array}$ & $\begin{array}{c}\text { Volume } \\
\text { Fraction } \\
(\%)\end{array}$ & $\begin{array}{c}\text { Average } \\
\text { Diameter } \\
(\mathrm{nm})\end{array}$ \\
\hline I & 330 & 20,700 & 10.1 & 0.05 & $1.5 \pm 0.2$ \\
\hline I & 365 & 20,700 & 2.2 & 0.12 & $3.6 \pm 0.6$ \\
\hline I & 405 & 20,700 & 4.8 & 0.24 & $3.8 \pm 0.8$ \\
\hline WF & 330 & 100,000 & 4.9 & 0.07 & $2.9 \pm 0.6$ \\
\hline
\end{tabular}

Table 2: Cluster statistics for each alloy and condition. N.B. Since the majority of clusters were observed to have nucleated on heterogeneous nucleation sites, $\mathrm{Nd}$ and Vf measurements are unlikely to accurately reflect the true global values within the material.

The mean composition of the clusters (not including clusters that had nucleated on carbidematrix interfaces) is displayed in Table 3 and the mean ratio of $\mathrm{Mn}: \mathrm{Ni}: \mathrm{Si}$ in the clusters detected in each condition is shown on a Gibbs triangle in Figure 5. The clusters in Alloy I appear to comprise of mostly $\mathrm{Ni}$, with the ratio of $\mathrm{Mn}$ :Si increasing as ageing temperature increases. Meanwhile, the clusters in alloy WF comprise of approximately equal parts of $\mathrm{Ni}$ and $\mathrm{Mn}$. 
Xiong et al. used thermodynamic models to predict stable compositions for Mn-Ni-Si-rich precipitates[12]. The clusters in alloy I after 20,700 hours of ageing at $330{ }^{\circ} \mathrm{C}$ and $365^{\circ} \mathrm{C}$ are similar to the predicted $\mathrm{T} 3\left(\mathrm{Mn}_{6} \mathrm{Ni}_{16} \mathrm{Si}_{7}\right)$ phase composition (Figure 5), whilst the clusters in the $405^{\circ} \mathrm{C}$ sample are closer to the predicted $\mathrm{T} 6$ composition range $\left(\mathrm{Mn}_{33.3} \mathrm{Ni}_{46} \mathrm{Si}_{20.7}-\right.$ $\left.\mathrm{Mn}_{33.3} \mathrm{Ni}_{54} \mathrm{Si}_{12.7}\right)$. However, the composition of the clusters in all conditions are offset from those predicted; this may be because the experimental temperatures are far from that used in the simulations $\left(277^{\circ} \mathrm{C}\right)$ to calculate the predicted phase compositions. The features observed in WF have a similar stoichiometry $\left(\mathrm{Mn}_{8} \mathrm{Ni}_{9} \mathrm{Si}_{2}\right)$ to that of the B2 phase[12,15].

\begin{tabular}{|c|c|c|c|c|c|c|c|}
\hline Alloy & $\begin{array}{c}\text { Ageing } \\
\text { Temperature } \\
\left({ }^{\circ} \mathrm{C}\right)\end{array}$ & $\mathrm{Ni}$ & $\mathrm{Mn}$ & $\mathrm{Si}$ & $\mathrm{Cu}$ & $\mathrm{P}$ & Other \\
\hline $\mathrm{I}$ & 330 & $58.4 \pm 1.5$ & $16.9 \pm 1.9$ & $22.0 \pm 1.0$ & $1.8 \pm 0.3$ & $0.3 \pm 0.1$ & $0.6 \pm 0.2$ \\
\hline $\mathrm{I}$ & 365 & $51.8 \pm 1.4$ & $22.8 \pm 2.8$ & $21.6 \pm 1.7$ & $1.7 \pm 0.2$ & $0.9 \pm 0.1$ & $1.3 \pm 0.1$ \\
\hline $\mathrm{I}$ & 405 & $54.4 \pm 2.5$ & $29.2 \pm 3.0$ & $12.7 \pm 1.3$ & $2.9 \pm 0.6$ & $0.0 \pm 0.0$ & $0.7 \pm 0.4$ \\
\hline WF & 330 & $44.5 \pm 1.9$ & $40.2 \pm 1.7$ & $12.3 \pm 1.0$ & $1.8 \pm 0.5$ & $0.8 \pm 0.4$ & $0.3 \pm 0.1$ \\
\hline
\end{tabular}

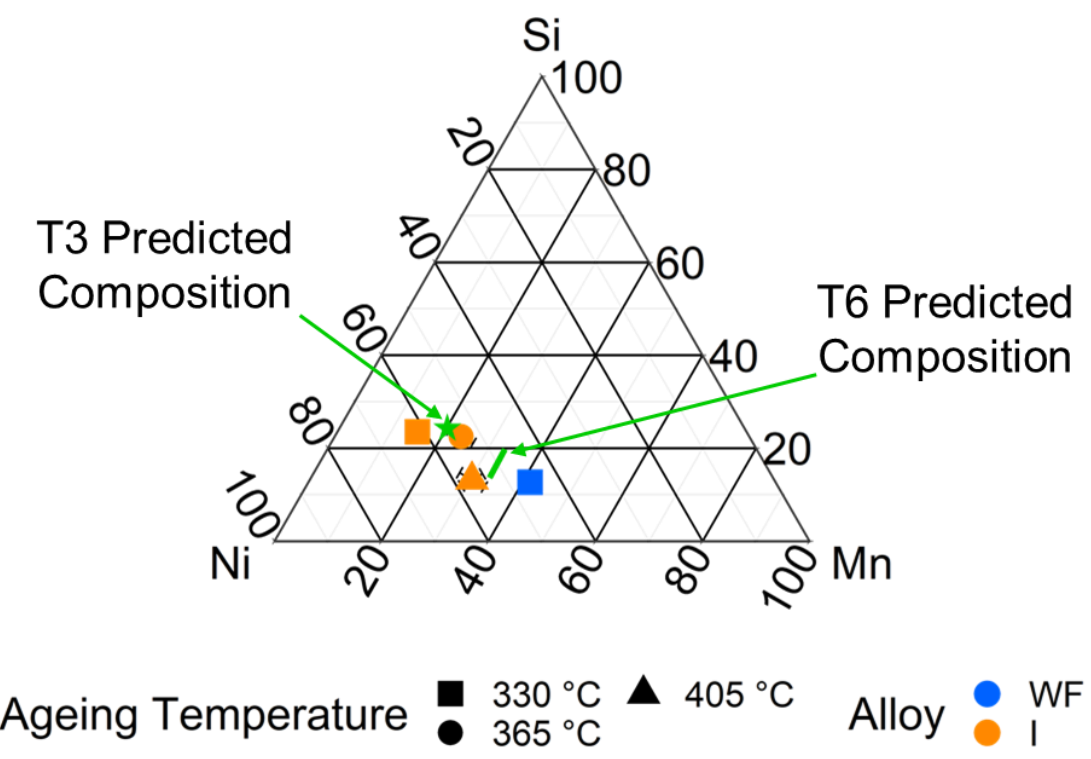

Figure 5: Gibbs triangle showing the mean ratio of Mn:Ni:Si in the clusters detected in each sample in this study. Error bars show the standard error of the measurements. The composition of the T3 phase and composition range of T6 predicted by Xiong et al.[12] are also shown.

There was a distinct difference between the compositions of the clusters that formed in each alloy. Comparing the composition of the clusters detected in alloy I at $330^{\circ} \mathrm{C}$ with those detected in alloy WF at the same temperature, it can be seen that the clusters in alloy I contained more $\mathrm{Ni}$ and $\mathrm{Si}$ than the clusters in WF. This difference is also reflected in the compositions of the two alloys, indicating that cluster composition is a function of bulk composition.

The vast majority of the Mn-Ni-Si-rich precipitates in this study were observed to have formed on heterogeneous nucleation sites; with homogeneously nucleated precipitates possibly being detected in the matrix of alloy $\mathrm{I}$ at $330^{\circ} \mathrm{C}$. This indicates that the kinetics of nucleation is lower in the matrix, possibly as result of the diffusion rates of $\mathrm{Mn}, \mathrm{Ni}$, and $\mathrm{Si}$ being much slower in the matrix than in the proximity of heterogeneous nucleation sites. 
The diffusion distances of $\mathrm{Cu}, \mathrm{Ni}, \mathrm{Mn}$, and $\mathrm{Si}$, respectively, in $\alpha-\mathrm{Fe}$ at $330{ }^{\circ} \mathrm{C}$ were estimated using the equations in Reference [29]:

$$
\sqrt{\bar{x}^{2}}=\sqrt{D_{b} t}
$$

Where, $x$ is diffusion distance in $\mathrm{m}, D_{b}$ is the diffusion coefficient at a given temperature in $\mathrm{m}^{2} / \mathrm{s}$, and $t$ is time in $\mathrm{s}$. Using data from the literature, $D_{b}$ was determined as follows:

$$
D_{b}=D_{b 0} \exp \left(-Q_{S D} / R T\right)
$$

where $D_{b 0}$ is the diffusion coefficient at infinite temperature $\left(\mathrm{m}^{2} \mathrm{~s}^{-1}\right), Q_{S D}$ is the activation energy for self-diffusion $\left(\mathrm{kJ} \mathrm{mol}^{-1}\right), \mathrm{R}$ is the gas constant, and $\mathrm{T}$ is the temperature in Kelvin.

Table 4 shows the calculated diffusion distances. Even after 20,000 hours at $330^{\circ} \mathrm{C}$, the diffusion distance of solute atoms within the matrix appears to be sufficiently high for atoms to have formed nuclei for precipitates. Therefore, the lack of Mn-Ni-Si-rich precipitates in the matrix is likely due to thermodynamic considerations. A possible explanation is that the volume free energy change $\left(\Delta G_{V}\right)$ to form precipitates of critical size for growth $\left(r^{*}\right)$ is higher in the matrix than at heterogeneous nucleation sites; potentially as a result of more free space at these heterogeneous nucleation sites. Previous studies have reported $\mathrm{Mn}-\mathrm{Ni}$-Sirich features nucleating as appendages to Cu-rich precipitates but not homogeneously[30], indicating that the barrier to nucleation is the rate-limiting step for matrix precipitation, especially at the lower undercoolings experienced at $365^{\circ} \mathrm{C}$ and $405^{\circ} \mathrm{C}$.

\begin{tabular}{|c|c|c|c|c|}
\hline \multirow{2}{*}{ Element } & \multirow{2}{*}{$\begin{array}{c}\mathrm{D}_{0} \\
\left(\mathrm{~cm}^{2} / \mathrm{s}\right)\end{array}$} & \multirow{2}{*}{$\begin{array}{c}\mathrm{QSD}_{\mathrm{SD}} \\
(\mathrm{kJ} / \mathrm{mol})\end{array}$} & \multicolumn{2}{|c|}{ Diffusion distance $(\mathrm{nm})$} \\
\cline { 4 - 5 } & 0.47 & 244 & 20,000 hours & 100,000 hours \\
\hline $\mathrm{Cu}$ & 1.40 & 246 & 1.6 & 3.5 \\
\hline $\mathrm{Ni}$ & 1.49 & 234 & 2.2 & 5.0 \\
\hline $\mathrm{Mn}$ & 0.78 & 220 & 22.2 & 17.7 \\
\hline $\mathrm{Si}$ & & & 249.6 \\
\hline
\end{tabular}

Table 4: Diffusions coefficients and calculated diffusion distances for $\mathrm{Cu}[31], \mathrm{N}[32], \mathrm{Mn}[33]$ and Si[34] at $330{ }^{\circ} \mathrm{C}$ for times of 20,000 hours and 100,000 hours. N.B. Do and QSD values are based on extrapolations of higher temperature experimental data. In the case of $\mathrm{Mn}$ and $\mathrm{Ni}$, the reference values relate to the ferromagnetic state of alpha iron, whereas in the case of silicon, no such values were available, so the extrapolation was made from data recorded in the paramagnetic temperature range. This leads to an overestimate of the true silicon diffusion distances, although the true values are still likely to be higher than for Mn or Ni.

The observation of Mn-Ni-Si-rich clusters in the matrix of alloy I at $330^{\circ} \mathrm{C}$ indicates that the energy barrier for nucleation is sufficiently low at this temperature and, given that reactor temperatures are lower than this, the nucleation of Mn-Ni-Si-rich precipitates may be relevant to RPV in-service temperatures.

To summarise, Mn-Ni-Si-rich precipitates have been observed to form in the absence of other precipitates in thermally-aged materials for the first time. Our findings indicate that their formation, particularly at heterogeneous nucleation sites, is thermodynamically favourable from $330^{\circ} \mathrm{C}$ up to $405^{\circ} \mathrm{C}$, supporting the findings in Reference [18]. However, the key nucleation mechanism for Mn-Ni-Si-rich precipitate formation is at dislocations and interfaces in the thermally-aged materials, as opposed to in the grain interiors in the neutronirradiated materials; this indicates that the features form at defect sites, and that precipitate formation and growth in neutron-irradiated materials is enhanced due to the production of vacancies during irradiation. Cluster composition was dependent on the initial composition of the matrix. This information can be used to better inform thermodynamic models that predict the stability of hardening features in RPV alloys, which in turn will permit the creation of more accurate lifetime prediction models for RPV safety cases. 
The observation of heterogeneous precipitation on dislocations implies the pinning of these defects. Also, precipitation at grain boundaries would be expected to inhibit the propagation of plastic flow between grains and, as a result, significant changes in the mechanical properties of these materials might be expected after ultra-long periods of thermal aging. These changes require investigation.

\section{Acknowledgements}

Funding: this work was supported by Rolls-Royce Plc. The atom probe facilities at the University of Oxford are funded by the EPSRC (EP/M022803/1). The authors acknowledge use of characterisation facilities within the David Cockayne Centre for Electron Microscopy, Department of Materials, University of Oxford, alongside financial support provided by the Henry Royce Institute (Grant ref EP/R010145/1).

Export Control Classification - Not Listed 02/06/20 @ Rolls-Royce 2020.

\section{Bibliography}

[1] P.B. Wells, T. Yamamoto, B. Miller, T. Milot, J. Cole, Y. Wu, G.R. Odette, Acta Mater. 80 (2014) 205-219.

[2] M.K. Miller, M.A. Sokolov, R.K. Nanstad, K.F. Russell, J. Nucl. Mater. 351 (2006) 187-196.

[3] M.K. Miller, K.F. Russell, J. Kocik, E. Keilova, J. Nucl. Mater. 282 (2000) 83-88.

[4] N. Almirall, P. Wells, T. Yamamoto, K. Wilford, T. Williams, N. Riddle, G.R. Odette, Acta Mater. Manuscript (2018) 119-128.

[5] P.D. Edmondson, C.M. Parish, R.K. Nanstad, Acta Mater. 134 (2017) 31-39.

[6] N. Almirall, P.B. Wells, H. Ke, P. Edmondson, D. Morgan, T. Yamamoto, G.R. Odette, Sci. Rep. 9 (2019) 9587.

[7] M.K. Miller, K.F. Russell, J. Nucl. Mater. 371 (2007) 145-160.

[8] M.K. Miller, K.A. Powers, R.K. Nanstad, P. Efsing, J. Nucl. Mater. 437 (2013) 107115.

[9] M.K. Miller, A.A. Chernobaeva, Y.I. Shtrombakh, K.F. Russell, R.K. Nanstad, D.Y. Erak, O.O. Zabusov, J. Nucl. Mater. 385 (2009) 615-622.

[10] K. Lindgren, M. Boåsen, K. Stiller, P. Efsing, M. Thuvander, J. Nucl. Mater. 488 (2017) 222-230.

[11] G.R. Odette, G.E. Lucas, Recent Progress in Understanding Reactor Pressure Vessel Steel Embrittlement, 1998.

[12] W. Xiong, H. Ke, R. Krishnamurthy, P.B. Wells, L. Barnard, G.R. Odette, D. Morgan, Mater. Res. Soc. Commun. 4 (2014) 101-105.

[13] S. Shu, P.B. Wells, G.R. Odette, D. Morgan, J. Nucl. Mater. 524 (2019) 312-322.

[14] P.B. Wells, T. Yamamoto, B. Miller, T. Milot, J. Cole, Y. Wu, G.R. Odette, Acta Mater. 80 (2014).

[15] G. Bonny, D. Terentyev, A. Bakaev, E.E. Zhurkin, M. Hou, D. Van Neck, L. Malerba, J. Nucl. Mater. 442 (2013) 282-291.

[16] M. Chiapetto, C.S. Becquart, C. Domain, L. Malerba, Nucl. Instruments Methods Phys. Res. Sect. B Beam Interact. with Mater. Atoms 352 (2015) 56-60. 
[17] M.J. Konstantinovic, I. Uytdenhouwen, G. Bonny, N. Castin, L. Malerba, P. Efsing, Acta Mater. 179 (2019) 183-189.

[18] N. Almirall, P.B. Wells, S. Pal, P.D. Edmondson, T. Yamamoto, K. Murakami, G.R. Odette, Scr. Mater. 181 (2020) 134-139.

[19] K. Lindgren, M. Boåsen, K. Stiller, P. Efsing, M. Thuvander, J. Nucl. Mater. 504 (2018) 23-28.

[20] P.D. Styman, J.M. Hyde, K. Wilford, A. Morley, G.D.W. Smith, Prog. Nucl. Energy 57 (2012) 86-92.

[21] B. Gault, M.P. Moody, J.M. Cairney, S.P. Ringer, Atom Probe Microscopy, 1st ed., Springer-Verlag New York, 2012.

[22] M.K. Miller, K.F. Russell, K. Thompson, R. Alvis, D.J. Larson, Microsc. Microanal. 13 (2007) 428-436.

[23] M.K. Miller, K.F. Russell, G.B. Thompson, Ultramicroscopy 102 (2005) 287-298.

[24] K. Thompson, D. Lawrence, D.J. Larson, J.D. Olson, T.F. Kelly, B. Gorman, Ultramicroscopy 107 (2007) 131-139.

[25] L.T. Stephenson, M.P. Moody, P.V. Liddicoat, S.P. Ringer, Microsc. Microanal. 13 (2007) 448-463.

[26] J.M. Hyde, C.A. English, in: Cited by 19 Get Access Vol. 650 (Symposium R Microstruct. Process. Irradiat. Mater., 2000, p. R6.6.

[27] L.T. Stephenson, A.V. Ceguerra, T. Li, T. Rojhirunsakool, S. Nag, R. Banerjee, J.M. Cairney, S.P. Ringer, MethodsX 1 (2014) 12-18.

[28] B.M. Jenkins, A.J. London, N. Riddle, J.M. Hyde, P.A.J. Bagot, M.P. Moody, Mater. Charact. 160 (2020) 110078.

[29] D.A. Porter, K.E. Easterling, M.Y.A. Sherif, Phase Transformations in Metals and Alloys (Revised Reprint), 3rd ed., CRC Press, 2009.

[30] P.D. Styman, Atomic Scale Studies of Thermally Aged Reactor Pressure Vessel Steels, University of Oxford, 2013.

[31] M.S. Anand, R.P. Agarwala, J. Appl. Phys. 37 (1966) 4248-4251.

[32] K. Hirano, M. Cohen, B.L. Averbach, Acta Metall. 9 (1961) 440-445.

[33] W.F. Gale, TotemeierT.C., eds., Smithells Metals Reference Book (Eighth Edition), Elsevier, 2004.

[34] R.J. Bjorg, D.Y.F. Lai, J. Appl. Physics1 41 (1970) 5193. 